\title{
Duration of recurrent ileitis after ileocolonic resection correlates with presurgical extent of Crohn's disease
}

\author{
G R D'Haens, A E Gasparaitis, S B Hanauer
}

\begin{abstract}
Crohn's disease of the terminal ileum recurs in a predictable sequence proximal to the ileocolonic anastomosis after surgical resection. To confirm the suspicion that the duration of recurrent ileitis correlates with the extent of presurgical disease, this study investigated 23 consecutive patients with recurrent Crohn's disease symptoms who had undergone ileocaecal resections between 1982 and 1992 at our institution and had both preoperative and postoperative small bowel follow through studies available for comparison. All films were reviewed by a blinded gastrointestinal radiologist using uniform criteria. Symptomatic recurrence was reported at a mean (SEM) of 29 (25) months after resection. Presurgical length of inflammation averaged 26 (15) (8-57) $\mathrm{cm}$ and at recurrence 24 (14) (7-55) cm. The correlation coefficient $(r)$ between pre and postsurgical extent of ileal disease was $0.70(p<0.0001)$. Seven patients had sequential small bowel series after 20 (10) (7-36) months without intervening surgery. The extent of measured inflammation between examinations correlated with $r=0.995(p<0.0001)$, showing the consistency of the measurement process. The close correlation between the duration of postoperative recurrence with the extent of presurgical disease is another example of individual patterns of recurrent Crohn's disease and is an additional factor to be considered when contemplating surgical resections.

(Gut 1995; 36: 715-717)
\end{abstract}

Keywords: Crohn's disease, ileocolonic resection, ileitis.

Departments of

Gastroenterology and Gastrointestinal Radiology, University of Chicago Medical Center, Chicago, USA G R D'Haens A E Gasparaitis $S$ B Hanauer

Correspondence to: Dr S Hanauer, Department of Gastroenterology, University of Chicago Medical Center, 5841 South Maryland Avenue, MC 4076, Chicago, IL 60637 , USA.

Accepted for publication 17 August 1994
The recurrence of Crohn's disease after surgical resection is very common. Reported frequencies have ranged from $50 \%$ to $90 \%$, depending on the definition used. Endoscopic signs of recurrence have been described in up to $73 \%$ of patients at one year and in $85 \%$ at three years after ileal resection. The severity of the endoscopic lesions has even been found to be predictive of symptomatic recurrence. ${ }^{1}$

The most restrictive definition of 'recurrence' is surgical reintervention, which is required in about 15 to $40 \%$ at 10 years and 50 to $70 \%$ at 20 years after initial resection. ${ }^{2-4}$ The frequency of clinical recurrence is higher, increasing with the length of follow up. Greenstein et al reported $60 \%$ recurrence at five years and $94 \%$ at 15 years after resection, and the National Cooperative Crohn's Disease Study (NCCDS) reported $78 \%$ recurrence at 20 years. $^{4-7}$

Factors that have been studied as possible predictors of recurrence include the site of involvement, the indication for surgery, and the preoperative duration of disease. Patients with diffuse ileocolonic inflammation and failure of medical treatment as an indication for surgery experience higher recurrence rates. ${ }^{3} 68$ Surgical studies have stressed the importance of disease free margins in resections ${ }^{9}$ and reported the presence of granulomas to be associated with higher recurrence rates, ${ }^{10}$ but this subsequently has not been confirmed. ${ }^{811} 12$ Smoking so far seems to be the only external factor that may play a part in the development of recurrent disease. ${ }^{13}$

The radiological abnormalities in small bowel Crohn's disease are considered unique and typical. Involved segments show focal ulcerations, granularity and nodularity $(60 \%)$, and tubular narrowing causing the typical 'string sign'. 'Spikes' point to the presence of fissures, while 'cobblestoning' reflects pseudopolyp formation. ${ }^{14}{ }^{15}$ Proximally to the diseased mucosa, a 'transition zone' can be distinguished with oedema and granularity, reflecting early changes in the villous structure. ${ }^{16}$ Most radiological studies suggest that the inflammation does not progress longitudinally over time. ${ }^{17}$

Recurrent disease after resection typically appears immediately proximally to the ileocolonic anastomosis. The radiological features are often identical to the abnormalities before surgery ${ }^{18}$ but overall radiological signs have correlated poorly with the clinical picture. ${ }^{19}$

The purpose of our study was to determine the relation between the extent of inflammation before surgical resection and at the time of recurrent symptoms.

\section{Methods}

We selected all the Crohn's disease patients from our inflammatory bowel diseases database who had ileal (with or without) resection between January 1982 and 1992 and had small bowel follow through studies at our radiology department before surgery and at the time of recurrent symptoms. The diagnosis of Crohn's disease was confirmed histologically on endoscopic biopsy specimens and on the resection 
TABLE I Patient data

\begin{tabular}{|c|c|c|c|c|c|}
\hline $\begin{array}{l}\text { Patients } \\
(n=23)\end{array}$ & $\begin{array}{l}\text { Sex } \\
(M / F)\end{array}$ & $\begin{array}{l}\text { Age at diagnosis } \\
\text { mean (SEM) }\end{array}$ & $\begin{array}{l}\text { Time from diagnosis } \\
\text { to 1st study (month) } \\
\text { mean (SEM) }\end{array}$ & $\begin{array}{l}\text { Time from } \\
\text { diagnosis to surgery } \\
\text { mean (SEM) }\end{array}$ & $\begin{array}{l}\text { Time from surgery to } \\
\text { recurrence (month) } \\
\text { mean (SEM) }\end{array}$ \\
\hline & $9 / 14$ & $20.9(7 \cdot 5)$ & $128 \cdot 7(61 \cdot 6)$ & $141 \cdot 1(64 \cdot 8)$ & $28.65(25.0)$ \\
\hline 1 & $\mathrm{~F}$ & 11 & 168 & 180 & 33 \\
\hline 2 & $\mathrm{~F}$ & 15 & 173 & 192 & 9 \\
\hline 3 & $M$ & 18 & 115 & 120 & 48 \\
\hline 4 & M & 14 & 167 & 169 & 49 \\
\hline 5 & $\mathrm{~F}$ & 22 & 83 & 87 & 46 \\
\hline 6 & $\mathrm{~F}$ & 38 & 34 & 67 & 96 \\
\hline 7 & $\mathrm{~F}$ & 18 & 232 & 249 & 12 \\
\hline 8 & $\mathrm{~F}$ & 10 & 32 & 33 & 76 \\
\hline 9 & $\mathbf{M}$ & 16 & 185 & 237 & 50 \\
\hline 10 & M & 9 & 83 & 90 & 54 \\
\hline 11 & $\mathrm{~F}$ & 35 & 105 & 106 & 3 \\
\hline 12 & $\mathrm{~F}$ & 29 & 185 & 221 & 8 \\
\hline 13 & M & 23 & 34 & 52 & 2 \\
\hline 14 & M & 22 & 242 & 244 & 12 \\
\hline 15 & M & 24 & 108 & 109 & 23 \\
\hline 16 & $\mathrm{~F}$ & 27 & 126 & 137 & 22 \\
\hline 17 & $\mathrm{~F}$ & 27 & 119 & 120 & 40 \\
\hline 18 & $\mathrm{~F}$ & 14 & 103 & 161 & 5 \\
\hline 19 & $\mathbf{M}$ & 24 & 240 & 241 & 19 \\
\hline 20 & M & 17 & 132 & 133 & 9 \\
\hline $21^{\star}$ & $\mathrm{F}$ & 20 & 89 & 90 & 12 \\
\hline $22^{\star}$ & $\mathrm{F}$ & 27 & 99 & 99 & 25 \\
\hline $23 t$ & $\mathbf{F}$ & 21 & 106 & 108 & 6 \\
\hline
\end{tabular}

^Previous ileocaecectomy; †two earlier ileal resections.

specimen. Surgical resections were performed because of intestinal obstruction or unresponsiveness to medical treatment and consisted of complete resection of the grossly diseased segment. None of the patients had intraabdominal fistulas or abscesses.

Most patients were referred by gastroenterologists and had small bowel studies done before the examinations in our service, but these were not included in our review. A number of patients (three of 23) had undergone an earlier ileo (caecal) resection (Table I).

The radiological technique consisted of a double contrast barium swallow with air insufflation through the rectum.

All the studies were reviewed in random order by a blinded gastrointestinal radiologist (AEG). Patients with multifocal disease and colonic Crohn's disease were excluded. If the length of ileal inflammation could not be measured exactly because of poor $x$ ray quality or overlying bowel loops, the case was excluded as well. The length of intestinal inflammation was measured with a flexible ruler in the centre of the lumen, beginning at the ileocaecal valve or the ileocolonic anastomosis (Table II).

TABLE II Extent of inflammation $(\mathrm{cm})$ before and after surgery

\begin{tabular}{llll}
\hline Patient & Before & Recurrence & After/before \\
\hline 1 & 13 & 19 & $1 \cdot 46$ \\
2 & 19 & 22 & $1 \cdot 16$ \\
3 & 9 & 8 & $0 \cdot 89$ \\
4 & 29 & 9 & $0 \cdot 31$ \\
5 & 45 & 34 & $0 \cdot 75$ \\
6 & 25 & 25 & $1 \cdot 00$ \\
7 & 36 & 21 & $0 \cdot 58$ \\
8 & 8 & 12 & $1 \cdot 5$ \\
9 & 17 & 40 & $2 \cdot 35$ \\
10 & 14 & 14 & $1 \cdot 00$ \\
11 & 40 & 37 & $0 \cdot 92$ \\
12 & 8 & 7 & $0 \cdot 87$ \\
13 & 50 & 25 & $0 \cdot 50$ \\
14 & 57 & 52 & $0 \cdot 91$ \\
15 & 14 & 11 & $0 \cdot 79$ \\
16 & 13 & 15 & $1 \cdot 15$ \\
17 & 39 & 40 & $1 \cdot 03$ \\
18 & 12 & 23 & 1.92 \\
19 & 38 & 15 & $0 \cdot 39$ \\
20 & 36 & 36 & $1 \cdot 00$ \\
21 & 15 & 15 & $1 \cdot 00$ \\
22 & 43 & 55 & $1 \cdot 28$ \\
23 & 18 & 18 & $1 \cdot 00$ \\
\hline
\end{tabular}

Disease involvement was defined as oedema, granularity, ulcers and nodularity, string sign or cobblestoning, and included the transition zone to normal mucosa. Measurements were done on overview films and rounded off to nearest full centimetre value. Spot films were used for orientation and detailed assessment of inflammatory changes.

Statistical analysis was done using the Minitab (PWS-Kent, Boston) correlation and regression methods.

\section{Results}

Patient and disease characteristics

Twenty three patients (nine male, 14 female) remained for comparison of length of disease and further analysis. Two patients had had earlier ileo(caecal) resections, and one patient had had two earlier ileal resections. The age at the diagnosis of Crohn's disease varied from 9 to 38 years (mean (SEM) $20.9(7.5)$ ). The preoperative small bowel follow through study was performed in our gastrointestinal radiology service between 32 and 242 months after the diagnosis of Crohn's disease had been made (mean (SEM) 128.7 (61.6)). Surgical resection was carried out between 33 and 249 months after diagnosis (mean 141.1 (64.8)). The time period from surgical resection to the recurrence of symptoms and the second small bowel study ranged from 2 to 96 months (mean 28.6 (25.0)).

\section{Extent of inflammation}

The extent of involvement on small bowel follow through before surgical resection ranged from $8 \mathrm{~cm}$ to $57 \mathrm{~cm}$ (mean $26 \cdot 0(15 \cdot 0) \mathrm{cm}$ ). At recurrence of symptoms, a mean of $28.6(25 \cdot 0)$ months after surgery, the length of inflammation on small bowel studies ranged from $7 \mathrm{~cm}$ to $55 \mathrm{~cm}$ (mean $24.0(13 \cdot 8) \mathrm{cm}$ ). The correlation coefficient $(r)$ between both studies was $0.70, \mathrm{p}<0.0001$ (Fig 1). Figure 2 shows an example of this close correlation between a patient's initial and recurrent disease.

Seven patients (five before, two after surgery) had two radiological studies performed without intervening surgery with time intervals ranging from 7 to 36 months (mean $20 \cdot 1(10 \cdot 1))$. The length of inflammation on both studies correlated highly $(r=0.995$, $\mathrm{p}<0.0001$ ), supporting the theory that the

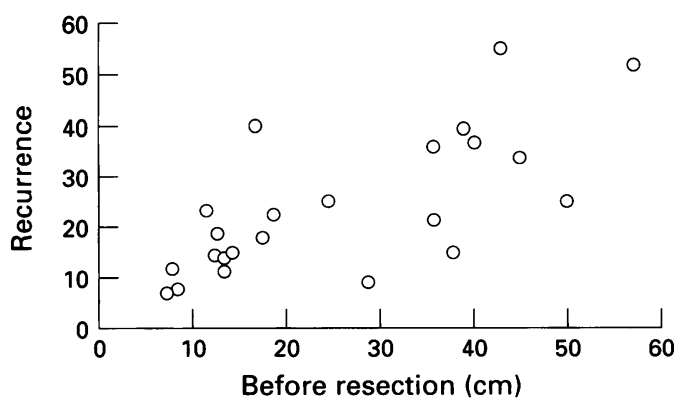

Figure 1: Correlation between the presurgical length of ileal Crohn's disease and the disease extent at symptomatic recurrence. $\mathrm{r}=0.70(p<0.0001)$. 


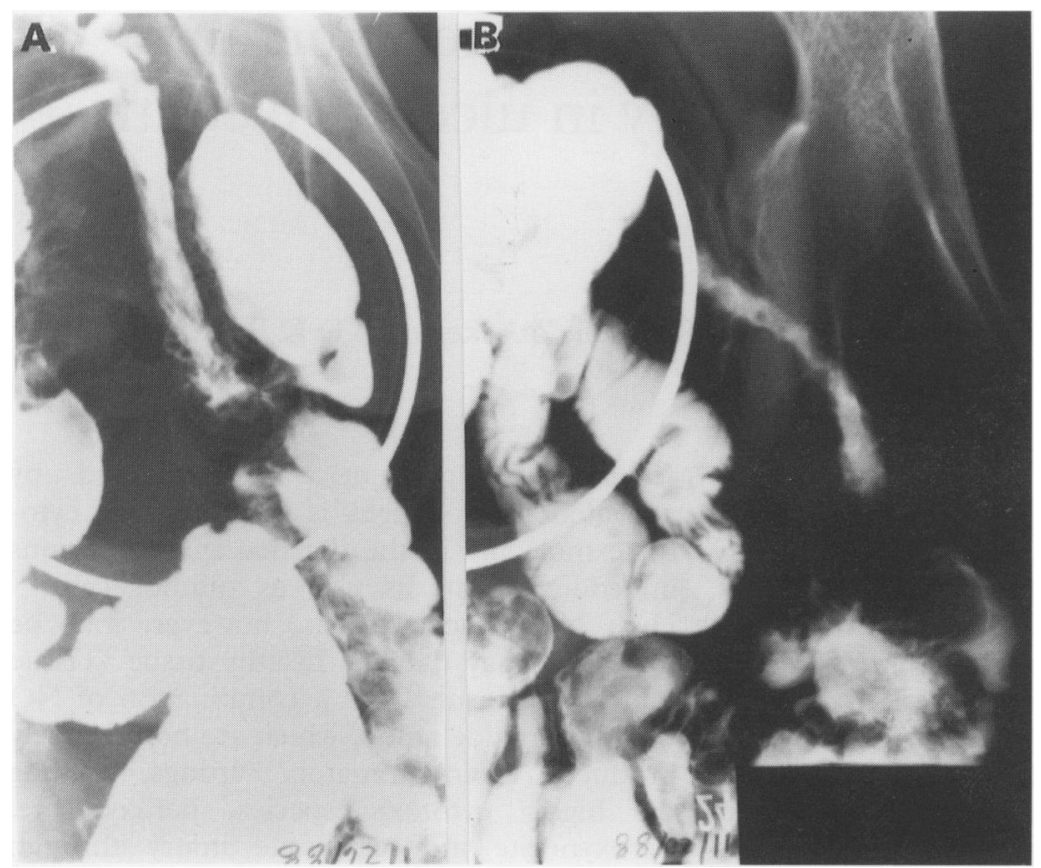

Figure 2: Example of a patient showing comparable length of ileal Crohn's disease on a preoperative small bowel study $(A)$ and the same study at symptomatic recurrence $(B)$.

inflammation generally does not extend proximally over time, and showing high reliability and consistency in the reading process (Fig 3).

\section{Discussion}

The extent of Crohn's ileitis and its prognostic significance after surgery has not been studied up to date. It is now widely recognised that the likelihood of disease recurrence after resection is very high, even up to one hundred per cent if microscopic criteria are used. Radiologists noted that recurrent Crohn's inflammation often presents on small bowel studies with similar features as seen on presurgical studies. Our study shows that the duration of recurrent disease in the neoterminal ileum also correlates with the presurgical extent of disease.

This finding has important consequences in the decision process regarding ileal (with or without caecal) resection and provides additional prognostic information. All medical efforts should be undertaken to avoid large resections, as the disease will tend to recur in a long bowel segment. On the other hand,

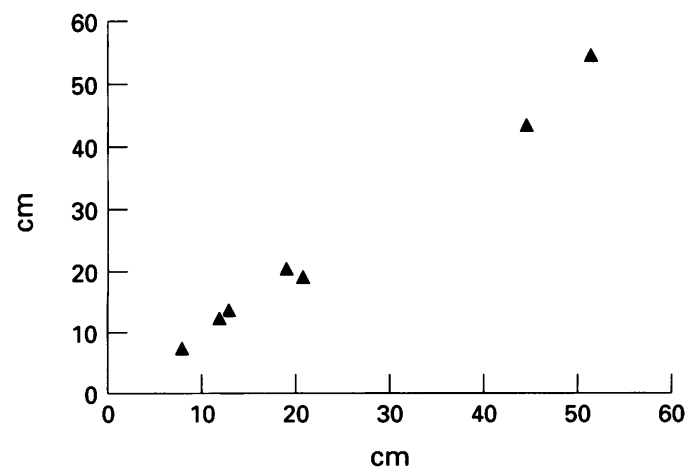

Figure 3: Correlation between the extent of ileal Crohn's disease on two different small bowel studies in the same patients, without intervening surgery $\mathrm{r}=0.995$ $(p<0.0001)$ patients with short ileal disease can be comforted that their disease is unlikely to recur in long intestinal segments.

The pathogenesis of both primary and recurrent Crohn's ileitis is still unknown. The terminal ileum is the most common site of inflammation, which may be related to the reflux of colonic content through a dysfunctional ileocolonic valve. The immune response in each individual patient seems to be equally aggressive after several surgeries.

If it is accepted that vascular involvement is a key factor in the pathogenesis, our findings could be explained by inflammation of vascular structures of the same calibre, the distal segments being most prone to ischaemic changes.

We conclude that the duration of recurrent ileal Crohn's disease after 'complete' surgical resection highly correlates with the presurgical extent of inflammation, even after multiple resections. Our data also support earlier data that the inflammation does not extend proximally over time.

1 Rutgeerts P, Geboes K, Vantrappen G, Beyls J, Kerremans $R$, Hiele M. Predictability of the postoperative course of Crohn's disease. Gastroenterology 1990; 99: 956-63.

2 Shivananda S, Hordijk ML, Pena AS, Mayberry JF. Crohn's disease: risk of recurrence and reoperation in a defined population. Gut 1989; 30: 990-5.

3 Whelan G, Farmer RG, Fazio VW, Goormastic M. Recurrence after surgery in Crohn's disease. Relationship to location of disease (clinical pattern) and surgical indication. Gastroenterology 1985; 88: 1826-33.

4 Sachar DB, Wolfson DM, Greenstein AJ, Goldberg J, Styczynski R, Janowitz HD. Risk factors for postoperative recurrence of Crohn's disease. Gastroenterology 1983; 85: 917-21.

5 Lock MR, Farmer RG, Fazio VW. Recurrence and reoperation for Crohn's disease. The role of disease location in prognosis. N Engl f Med 1981; 304: 1586-8.

6 Greenstein AJ, Sachar DB, Paternack BS, Janowitz HD. Reoperation and recurrence in Crohn's colitis and ileocolitis crude and cumulative rates. $N$ Engl $f$ Med 1975; 293: 685-90.

7 Mekhijan HS, Switz DM, Watts D, Deren JJ, Katon RM, Beman FM. National Cooperative Crohn's Disease study: factors determining recurrence of Crohn's disease after factors determining recurrence of Crohn's

8 Griffiths AM, Wesson DE, Shandling B, Corey M, Sherman PM. Factors influencing postoperative recurrence of Crohn's disease in childhood. Gut 1991; 32: 491-5.

9 Wolff BG, Beart RW, Frydenberg HB, Weiland LH, Agrez MV, Ilstrup DM. The importance of disease-free margins in resections for Crohn's disease. Dis Colon Rectum 1983; 26: $239-43$.

10 Lindhagen T, Ekelund G, Leandoer L, Hildell J, Lindstrom C, Wenckert A. Recurrence rate after surgical treatment of Crohn's disease. Scand $f$ Gastroenterol 1983; 18: $1037-44$.

11 Heuman R, Boeryd B, Bolin T, Sjodahl R. The influence of disease at the margin of resection on the outcome of

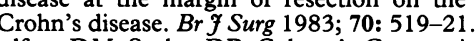

12 Wolfson DM, Sachar DB, Cohen A, Greenstein AJ, Gelernt IM, Goldberg J, et al. Granulomas do not affect postoperative recurrence rates in Crohn's disease. Gastroenterology 1982; 83: 405-9.

13 Sutherland LR, Ramcharan S, Bryant H, Fick G. Effect of cigarette smoking on recurrence of Crohn's disease. Gastroenterology 1990; 98: 1123-8.

14 Glick SN. Crohn's disease of the small intestine. Radiol Clin North Am 1987; 25: 25-45.

15 Pringot J, Bodart P. Inflammatory diseases. In: Margulis AR, Burchenne HJ, eds. Alimentary tract radiology. Vol 1. AR, Burchenne HJ, eds. Alimentary tract radiology.

16 Engelholm L, Mainguet P, Potvliege P. Radiology in early Crohn's disease of small intestine. In: Weterman IT, Pena AS, Booth CC, eds. The management of Crohn's disease. Proceedings of the workshop on Crohn's disease. Amsterdam: Excerpta Medica, 1976: 73-6.

17 Hildell J, Lindstrom C, Wenckert A. Radiographic appearance in Crohn's disease: II. The course as reflected at repeat radiography. Acta Radiol Diagn 1979; 20: 933-44.

18 Amman RW, Bocjkus HL. Pathogenesis of regional enteritis based on histological study of forty cases. Arch Intern Med 1961; 107: 504 .

19 Goldberg HI, Caruthers SB, Nelson JA, Singleton JW. Radiographic findings of the national cooperative Crohn's disease study. Gastroenterology 1979; 77: 925-37. 